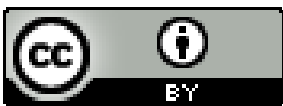

\title{
MOVIMENTO SOCIAL NEGRO: CAMINHOS EMANCIPATÓRIOS NA LUTA PELA EDUCAÇÃO
}

\author{
Danielle Celi dos Santos Scholz Pereira ${ }^{1}$ \\ Cláudia Rodrigues de Freitas ${ }^{2}$
}

Resumo: O presente artigo tem como objetivo delinear as lutas empreendidas pelo Movimento Social Negro no âmbito da educação, por meio de um resgate histórico, no qual os avanços, identificados no papel emancipatório da população negra, são a marca mais importante entre as conquistas alcançadas. Os caminhos percorridos na busca teórica foram realizados por meio da verificação de produções no Banco de Teses e Dissertações da CAPES (Coordenação de Aperfeiçoamento de Pessoal de Nível Superior) e Scielo (Scientific Electronic Library Online) e documentos e normativas do Ministério da Educação (MEC), disponíveis on-line. Os resultados demonstram protagonismo do Movimento Social Negro na construção de políticas públicas educacionais, que possuem o desafio cotidiano de enfrentamento do racismo e discriminação racial.

Palavras-chave: Movimento Social Negro; Educação; Lei Federal 10.639; Aluno Negro.

\section{BLACK SOCIAL MOVEMENT: EMANCIPATORY PATHS IN THE STRUGGLE FOR EDUCATION}

\begin{abstract}
This paper aims to outline the struggles undertaken by the Black Social Movement in the field of education, through a historical rescue, in which the advances identified in the emancipatory role of the black population are the most important mark among its achievements. The paths taken in the theoretical search were carried out through the verification of productions in the Bank of Theses and Dissertations of CAPES (Coordination for the Improvement of Higher Education Personnel) and Scielo (Scientific Electronic Library Online) and documents and regulations of the Ministry of Education (MEC), available online. The results show the role of the Black Social Movement in the construction of educational public policies, which have the daily challenge of confronting racism and racial discrimination.
\end{abstract}

\footnotetext{
${ }^{1}$ Mestre em Educação pela Universidade Federal do Rio Grande do Sul. Enfermeira do Centro de Atenção Psicossocial Infanto-juvenil CAPSij Arco-íris no município de Canoas/RS. E-mail: dani.scholz@hotmail.com

${ }^{2}$ É Professora na área de Educação Especial, Saúde e Processos Inclusivos, na Graduação e no Programa de Pós-Graduação em Educação, na Universidade Federal do Rio Grande do Sul. Coordena o NEPIE (Núcleo de Estudos em Políticas de Inclusão Escolar) na UFRGS. E-mail: freitascrd@gmail.com
}

Revista da ABPN • v. 12, n. Ed. Especial - Caderno Temático: "Africanos, escravizados, libertos biografias, imagens e experiências atlânticas” • agosto de 2020, p. $734-754$ 


\section{O.man}

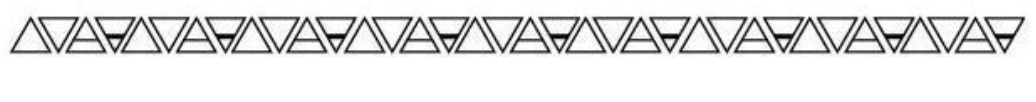

Keywords: Black Social Movement; Education; Federal Law 10,639; Black Student.

\section{MOVIMIENTO SOCIAL NEGRO: CAMINOS EMANCIPADORES EN LA LUCHA POR LA EDUCACIÓN}

Resumen: Este artículo tiene como objetivo trazar las luchas emprendidas por el Movimiento Social Negro en el campo de la educación, a través de un rescate histórico, que permitió identificar avances en el papel emancipatorio de la población negra, siendo una marca importante de los resultados obtenidos. El trayecto teórico se realizó a través de la búsqueda y verificación de producciones en el Banco de Tesis y Disertaciones de CAPES (Coordenação de Aperfeiçoamento de Pessoal de Nivel Superior), Scielo (Scientific Electronic Library Online), documentos y reglamentos del Ministerio de Educación (MEC), disponibles en los respectivos sitios web. Los resultados exponen el protagonismo del Movimiento Social Negro en la construcción de políticas públicas educativas para el desafío cotidiano de enfrentar el racismo y la discriminación racial.

Palabras-clave: Movimiento Social Negro; Educación; Ley Federal 10.639; Estudiante Negro.

\section{MOUVEMENTS SOCIAUX NOIRS: LES VOIES EMANCIPATRICES DANS LA LUTTE POUR L'EDUCATION}

Résumé: Cet article vise à retracer les luttes entreprises par les Mouvements Sociaux Noirs dans le domaine de l'éducation, à travers un sauvetage historique, dans lequel les avancées identifiées dans le rôle émancipateur de la population noire sont la marque la plus importante parmi les conquêtes obtenues. Les parcours empruntés dans la recherche théorique ont été menés à travers la vérification des études et des travaux de la Banque de Thèses et de Mémoires de la CAPES (Coordenação de Aperfeiçoamento de Pessoal de Nivel Superior) et Scielo (Scientific Electronic Library Online) et des documents et des réglementations du Ministère de l'Éducation (MEC) disponibles en ligne. Les résultats démontrent le rôle des Mouvements Sociaux Noirs dans la construction de politiques publiques éducatives, qui font face au défi quotidien dans la lutte contre le racisme et la discrimination raciale.

Mots-clés: Mouvements Sociaux Noirs ; Éducation ; Loi Fédérale n 10639 ; Élève noir.

Neste artigo, entende-se por Movimento Social Negro o conjunto de movimentos sociais com extensa trajetória de enfrentamento nas discussões e na produção de conhecimento relacionados à temática racial no Brasil. Suas lutas pelo combate ao

Revista da ABPN • v. 12, n. Ed. Especial - Caderno Temático: "Africanos, escravizados, libertos biografias, imagens e experiências atlânticas” • agosto de 2020, p. 734-754 
racismo e discriminação racial, que marginaliza a população negra, utilizaram-se de diferentes estratégias de mobilização social, atravessando diversas fases na história do Brasil.

Este estudo tem como objetivo delinear as lutas empreendidas pelo Movimento Social Negro, com foco no âmbito da educação, por meio de um resgate histórico, no qual, salientar-se-ão os avanços, identificados no papel emancipatório da população negra, como a marca mais importante entre as conquistas alcançadas.

Segundo Domingues (2007), pode-se dividir, no Brasil, o Movimento Social Negro em três fases distintas: a primeira compreendendo os anos de 1889 a 1937, tendo início, dessa forma, no período pós-abolição (organização de clubes, centros cívicos, associações e entidades políticas, de caráter social). A segunda, abrangendo os anos de 1945 a 1964, período de retomada da atuação no campo político, educacional e cultural, passando a enfatizar a luta pela conquista dos direitos civis. Os caminhos da então terceira fase (1978-2000), no qual emergem inúmeras entidades negras, sendo a maior delas o Movimento Negro Unificado (MNU).

Anota-se que no final dos anos 1970, os movimentos sociais antirracistas vão se tornando mais combativos e contundentes em relação às desigualdades e à discriminação racial no Brasil. A oposição à ditadura militar (1964-1985) e também o processo de redemocratização contribuem para que a terceira fase do Movimento Social Negro seja marcada por grande mobilização social e política (ROCHA, 2005).

A influência externa, nesse período, ocorre por meio de informações sobre a movimentação política de negros contra o racismo em países como os Estados Unidos e a África do Sul. O Movimento Social Negro, agregando intelectuais em todo o Brasil, acompanhava os movimentos de direitos civis e as ações do grupo Black Power nos Estados Unidos, onde se propagam as ideias em defesa de direitos e oportunidades iguais para os negros norte-americanos (MESSIA, 2009; ALBUQUERQUE; FRAGA; FILHO, 2006).

Entre as centenas de entidades negras que emergem nesse momento no Brasil, o Movimento Negro Unificado $(\mathrm{MNU})^{3}$ foi decisivo nas discussões sociais e políticas,

\footnotetext{
${ }^{3}$ O Movimento Unificado Contra a Discriminação Racial (MUCDR) foi criado em 7 de julho de 1978 em ato público em repúdio à discriminação racial sofrida por quatro jovens no Clube de Regatas Tietê. No seu
}

Revista da ABPN • v. 12, n. Ed. Especial - Caderno Temático: "Africanos, escravizados, libertos biografias, imagens e experiências atlânticas" • agosto de 2020, p. $734-754$ 
reintroduzindo e ressignificando o conceito de raça. Traziam como objetivo denunciar as desigualdades entre brancos e negros na luta pela conscientização e valorização da cultura negra (ROCHA, 2005).

Conforme Silva (2012), o MNU alicerçou suas ações em bases teóricas a partir de pesquisas $^{4}$ de intelectuais da área com argumentos irrefutáveis no que concerne ao racismo no Brasil. A partir dessas bases, o Movimento Social Negro vai construir uma crítica contundente à ideia de miscigenação como suporte para a organização do discurso sobre a identidade nacional e as relações étnico-raciais no país.

Schwarcz (2009) enfatiza que o Movimento é a marca da contestação, por parte da população negra, de uma democracia racial, visto as grandes diferenças sociais em relação ao acesso à educação, lazer e distribuição de renda. O Movimento Negro Unificado (MNU), então, fortalece-se na luta por essas questões juntamente a outras organizações paralelas sensíveis à causa que se agregam às lutas.

No cenário nacional de mobilização no combate ao racismo e discriminação racial, o MNU empreende continuamente seus enfrentamentos. Destaca-se, no ano de 1995, a Marcha Zumbi dos Palmares contra o racismo, pela cidadania e pela vida, contando com a participação de 30 mil manifestantes. Como resultado dessa mobilização, foi entregue, ao então presidente da República, o Programa de Superação do Racismo e da Desigualdade Racial, contendo um diagnóstico identificando a situação social, econômica, educacional e de saúde da população negra. Esse documento exigia uma posição do governo brasileiro diante da necessária superação do racismo. (SILVA, 2012; GOMES, 2011a).

É nesse contexto que o Movimento Social Negro pauta a luta pelas Políticas de Ações Afirmativas. Conforme Telles (2003), esse debate é realizado no "Seminário

$1^{\circ}$ Congresso, o MNUCDR como luta prioritária do movimento foi pautado ações contra a discriminação racial. Neste evento seu nome passou a ser chamado de Movimento Negro Unificado (MNU) (DOMINGUES, 2007). Também no ano de 1978, o 13 de Maio, data comemorativa da abolição, é substituída pelo 20 de Novembro (data da morte de Zumbi), como dia da Consciência Negra (SILVA, 2012, p.206).

${ }^{4}$ Durante os anos 1960 e 1970 uma série de pesquisas contribuiu para recolocar o problema das relações "raciais" no Brasil. Esses trabalhos, majoritariamente de cunho sociológico, como os de Fernando Henrique Cardoso, Capitalismo e escravidão no Brasil meridional (1962); de Otávio Ianni, As Metamorfoses do Escravo (1962); e de Florestan Fernandes, A integração do Negro na Sociedade de Classes (1965), demonstraram como a herança escravista havia criado barreiras importantes para o processo de integração do negro na sociedade capitalista brasileira (SILVA, 2012, p.205).

Revista da ABPN • v. 12, n. Ed. Especial - Caderno Temático: "Africanos, escravizados, libertos biografias, imagens e experiências atlânticas" • agosto de 2020, p. $734-754$ 
Internacional sobre Multiculturalismo e Racismo" no ano de 1996, mesmo período no qual foi lançado o Programa Nacional dos Direitos Humanos (PNDH), constatando a necessidade de implementação de políticas de curto, médio e longo prazos, incluindo-se o desenvolvimento de ações reparatórias em relação a populações historicamente excluídas, como população negra, mulheres e indígenas.

É também nesse momento histórico que se realiza uma inflexão em relação ao lugar da questão racial na política pública, sobretudo no campo educacional, conjuntura esta que é reforçada com marcante participação do Movimento Social Negro na III Conferência Mundial contra o Racismo, a Discriminação Racial, a Xenofobia e Formas Correlatas de Intolerância, promovida pela Organização das Nações Unidas (ONU), em 2001, na cidade de Durban, na África do Sul. (GOMES, 2011a).

A conferência em Durban possui uma particularidade, uma vez que foram pleiteados e declarados não apenas o reconhecimento das explorações ou discriminações, seja contra grupos étnicos, culturais ou de gênero, como também o pleito pela urgente retratação dos culpados (colonizadores e exploradores) e a justa reparação aos povos atingidos, destacando-se os afrodescendentes e indígenas da América Latina (CALDAS; SANTOS; SANTOS, 2011).

Ressalta-se que a delegação brasileira em Durban foi a maior das delegações e a participação do Movimento Social Negro brasileiro pode ser refletida no pósConferência, pois o governo, concretamente, começa a assumir e compreender a importância das Políticas de Ações Afirmativas como tentativa de garantir a igualdade entre brancos e negros (MESSIAS, 2009). No que tange às mudanças acerca das relações raciais pós-Conferência de Durban, Maggie e Fry (2004) asseveram que:

\footnotetext{
As medidas pós-Durban, ao proporem ações afirmativas em prol da "população negra", entre elas o reconhecimento oficial da legitimidade de reparações para com a escravidão e cotas para negros nas universidades públicas. [...] Ações afirmativas implicam, evidentemente, imaginar o Brasil composto não de infinitas misturas, mas de grupos estanques: os que têm e os que não têm direito à ação afirmativa, no caso em questão, "negros" e "brancos" (MAGGIE E FRY, 2004, p. 67, 68).
}

As Políticas de Ações Afirmativas são um conjunto de políticas públicas para proteger minorias e grupos que, em uma determinada sociedade, tenham sido discriminados no passado. Nesse contexto, as políticas de reparação de cunho racial

Revista da ABPN • v. 12, n. Ed. Especial - Caderno Temático: "Africanos, escravizados, libertos biografias, imagens e experiências atlânticas” • agosto de 2020, p. $734-754$ 
buscam a correção das desvantagens oriundas da desigualdade racial advindas da discriminação racial e do racismo na sociedade Brasileira (OLIVEN, 2007).

Enquanto política de reparações com vistas à inclusão social, considera-se relevante compreender que:

[...] a demanda por reparações visa que o Estado e a sociedade tomem medidas para ressarcir os descendentes de africanos negros dos danos psicológicos, materiais, sociais, políticos e educacionais sofridos sob o regime escravista, bem como em virtude das políticas explícitas ou tácitas de branqueamento da população, de manutenção de privilégios exclusivos para grupos com poder de governar e de influir na formulação de políticas, no pós-abolição. Visa também a que tais medidas se concretizem em iniciativas de combate ao racismo e a toda sorte de discriminações. (BRASIL, 2004, p.11).

Neste contínuo processo de lutas, destaca-se como avanço na garantia de políticas públicas, em 2003, a criação da Secretaria Especial de Políticas de Promoção da Igualdade Racial (SEPPIR) e da Secretaria de Educação Continuada, Alfabetização e Diversidade (Secad) ${ }^{5}$. Também em 2003, é sancionada a Lei Federal no $10.639 / 2003$, alterando a Lei no 9.394/96, conhecida como Lei de Diretrizes e Bases da Educação (LDB) (GOMES, 2011a; SILVA, 2012). As alterações da referida Lei, na LDB, são nos artigos 26-A e 79$\mathrm{B}$, tornando obrigatório o ensino de história e cultura afro-brasileira e africana nas escolas públicas e privadas de ensino fundamental e médio (BRASIL, 2003).

As Políticas de Ações Afirmativas de caráter étnico-racial na educação passaram a ser particularmente apoiadas com a promulgação da mencionada Lei. Conforme documento do Ministério da Educação (MEC) intitulado Relações étnico-raciais e de gênero: inclusão social a inserção dessa temática no currículo propõe desconstruir o mito da democracia racial e a crença de que negros não atingem os mesmos patamares de brancos por falta de competência, promovendo ainda a possibilidade à população negra de conhecer sua verdadeira história e cultura. (BRASIL, 2007).

\footnotetext{
${ }^{5}$ A Secretaria de Educação Continuada, Alfabetização e Diversidade (Secad), criada em 2004, tem como objetivo contribuir para a redução das desigualdades educacionais por meio de políticas públicas que ampliem o acesso à educação continuada e que sejam voltadas para os segmentos da população vítima de discriminação e de violência, incluindo indígenas e quilombolas. Após reestruturação, passou a ser composta também pelo eixo da inclusão - conforme o Decreto n. ${ }^{\circ}$ 7.690/2012 (Secadi) - e a desenvolver o fortalecimento do desenvolvimento inclusivo dos sistemas de ensino e promoção da educação inclusiva. (BRASIL, 2009; BRASIL, 2011).
}

Revista da ABPN • v. 12, n. Ed. Especial - Caderno Temático: "Africanos, escravizados, libertos biografias, imagens e experiências atlânticas" • agosto de 2020, p. $734-754$ 
Outro importante movimento foi o projeto de Lei $n^{0} 3.627 / 2004^{6}$ que prevê reserva de no mínimo 50\% de vagas em universidades públicas em cada concurso vestibular para estudantes oriundos da rede pública, com percentual mínimo para a população de negros e indígenas. Desse modo, por meio de constantes debates e mobilização do Movimento Social Negro, a reserva de cotas para negros foi sendo discutida e implantada de forma progressiva e com diferentes experiências no país (SILVÉRIO, 2007).

Dando continuidade ao processo de avanços, destaca-se, ainda, no ano de 2005, a introdução da obrigatoriedade de classificação racial dos estudantes em todos os níveis no Censo Escolar (Educacenso). Sendo o Censo o principal instrumento de coleta de informações da Educação Básica, a inclusão da informação sobre cor/raça obtida é capaz de revelar, por exemplo, como a desigualdade étnico-racial tem influência sobre a trajetória dos alunos (BRASIL, 2015).

A partir deste caminho inicial trilhado frente as importantes transformações alcançadas por meio das intensas reivindicações do Movimento Social Negro, este estudo bibliográfico está organizado em três subitens, com momentos históricos que contemplam avanços e retrocessos na busca pelo acesso e garantia da educação a população negra no país. Ressalta-se neste contexto a ênfase na atuação emancipatória do Movimento Social Negro que permeia estes processos.

\section{OS CAMINHOS PERCORRIDOS}

O percurso da pesquisa se constitui na investigação acerca do resgate histórico que define o rastro dos movimentos emancipatórios e conquistas, no âmbito da educação, da população negra no Brasil. A busca teórica foi realizada por meio da verificação de produções no Banco de Teses e Dissertações da CAPES (Coordenação de

\footnotetext{
${ }^{6} \mathrm{O}$ respectivo projeto foi promulgado pela Lei $\mathrm{n}^{\mathrm{o}} 12.711$ de 29 de agosto de 2012 . Prevê $50 \%$ de reserva aos estudantes oriundos de famílias com renda igual ou inferior a 1,5 salário-mínimo per capita em instituições federais, de ensino técnico e de nível médio. As vagas de que trata o art. 4o desta Lei serão preenchidas por autodeclarados pretos, pardos e indígenas e por pessoas com deficiência, nos termos da legislação, em proporção ao total de vagas no mínimo igual à proporção respectiva de pretos, pardos, indígenas e pessoas com deficiência na população da unidade da Federação onde está instalada a instituição, segundo o último censo do IBGE. www.planalto.gov.br/ccivil_03/_ato2011-2014/2012/lei/112711.htm
}

Revista da ABPN • v. 12, n. Ed. Especial - Caderno Temático: "Africanos, escravizados, libertos biografias, imagens e experiências atlânticas” • agosto de 2020, p. $734-754$ 
Aperfeiçoamento de Pessoal de Nível Superior) e Scielo (Scientific Electronic Library Online), utilizando os descritores: Movimento Negro; Educação e Lei Federal nº 10.639.

Documentos e normativas do Ministério da Educação (MEC), disponíveis on-line, também foram utilizados, facilitando a análise do percurso das políticas públicas educacionais para a educação das relações étnico-raciais e da Lei Federal nº 10.639/2003.

Os resultados da pesquisa foram organizados em três grandes tópicos analisadores que contêm uma linha de tempo envolvendo o contex to educacional e a população negra, bem como os movimentos históricos que contemplam avanços e retrocessos na busca pelo acesso e garantia da educação.

\section{ENTRE ESCRAVIZADOS E LIBERTOS: ONDE ESTÁ A EDUCAÇÃO?}

O contexto de acesso e permanência da população negra na educação brasileira é permeado por períodos históricos de interdições e lutas pela garantia deste direito. Reitera-se que esses movimentos se iniciam no período escravocrata e permanecem em constante debate atualmente, sendo demarcados por avanços e disputas sociais.

A educação no sistema escravocrata, diferentemente do período de colonização jesuítica, é caracterizada pela substituição dos cursos seriados por aulas avulsas ministradas por professores improvisados. Tal conjuntura mantém-se até 1808, com a chegada da Coroa Portuguesa no Brasil e a construção de uma organização em cursos "menores" e "maiores" e primário-secundário e superior, respectivamente (SILVA; ARAÚJO, 2005).

Em relação ao acesso da população negra escravizada, Silva e Araújo (2005) afirmam que esta parcela da população sofreu com impeditivos de frequentar a escola formal, pois "era restrita, por lei, aos cidadãos brasileiros automaticamente esta legislação (art. 6, item 1 da Constituição de 1824) coibia o ingresso da população negra escrava, que era, em larga escala, africana de nascimento" (SILVA e ARAÚJO, 2005, p.97).

A chamada Reforma de Couto Ferraz - Decreto ${ }^{\circ} 1.331$ de 17 de fevereiro de 1854 - instituía a obrigatoriedade da escola primária para crianças maiores de sete anos e a gratuidade das escolas primárias e secundárias da Corte. Entretanto, no Decreto, no artigo 69, fica descrito que não serão admitidos à matrícula: “ $§ 1^{\circ}$ os meninos que

Revista da ABPN • v. 12, n. Ed. Especial - Caderno Temático: "Africanos, escravizados, libertos biografias, imagens e experiências atlânticas" • agosto de 2020, p. $734-754$ 
padecerem moléstias; contagiosas, $\S 2^{\circ}$ os que não tiverem sido vacinados e $\S 3^{\circ}$ os escravos" (BRASIL, 1854).

Nesses tempos, para Silva e Araújo (2005), o conteúdo dessa legislação previa a exclusão dos negros escravizados, adultos e crianças, além de associá-los às doenças contagiosas da época. Entretanto, descrevem movimentos de resistência em outros espaços e situações nos quais as pessoas escravizadas passaram a ser alfabetizadas como

observação silenciosa das aulas das sinhás-moças e da instrução religiosa dos padres. [...]. Outra possibilidade é a do encaminhamento de escravos do sexo masculino às escolas vocacionais ou de aprendizado e o ensino das letras por aqueles que as tinham treinado numa profissão (SILVA; ARAÚJO, 2005, p. 69).

Nessas circunstâncias, são reconhecidas as constantes linhas de fuga e movimentos na busca de transformação do lugar social instituído para a população negra escravizada. $\mathrm{O}$ acesso ao mínimo de instrução e a aproximação com a educação negados de diferentes modos, são revertidos em formas também diversas e constantes na história.

Em relação ao contexto educacional e ao período escravocrata, com suas interdições ligadas às pessoas escravizadas, torna-se necessário um olhar atento acerca da Lei $\mathrm{n}^{\circ}$ 2.040/1871, promulgada em 1871, conhecida como "Lei do Ventre Livre". É previsto no artigo 1 dessa legislação: "os filhos de mulher escrava que nascerem no Império desde a data desta lei serão considerados de condição livre" (BRASIL, 1871).

De acordo com Fonseca (2001), essa Lei marca um dos pontos históricos de tensões abolicionistas, tendo como uma de suas estratégias a libertação dos nascidos de mulheres escravizadas e a inserção destes na educação formal garantida pelo Estado. Salienta-se que essa regulamentação incidiria sob a única fonte legal de escravidão que se encontrava limitada desde o ano de $1850^{7}$, a partir da proibição do tráfico de africanos.

Quanto ao encaminhamento das crianças nascidas em condição de liberdade, segundo a Lei, fica exposto no artigo 1 , parágrafo $1^{\circ}$

\footnotetext{
${ }^{7}$ A chamada Lei Eusébio de Queirós proibiu o tráfico em 1850 depois de tantos enfrentamentos com o governo britânico. Mais conhecida como "lei para inglês ver", apresentou poucos avanços iniciais no seu objetivo, pois o tráfico, sobretudo o interno, continuara, assim como a apologia que ainda se fazia presente na boca dos mesmos que tinham sido obrigados a proibi-lo de vez (BOSI, 1988).
}

Revista da ABPN • v. 12, n. Ed. Especial - Caderno Temático: "Africanos, escravizados, libertos biografias, imagens e experiências atlânticas” • agosto de 2020, p. $734-754$ 
§1.Os ditos filhos menores ficarão em poder o sob a autoridade dos senhores de suas mães, os que terão obrigação de criá-los e tratá-los até a idade de oito anos completos. Chegando o filho da escrava a esta idade, o senhor da mãe terá opção, ou de receber do Estado a indenização de $600 \$ 000$, ou de utilizar-se dos serviços do menor até a idade de 21 anos completos. [...] O Governo poderá entregar a associações por ele autorizadas, os filhos das escravas, nascidos desde a data desta lei, que sejam cedidos ou abandonados pelos senhores delas (BRASIL, 1871, p.1).

Conforme Gonçalves (2010), o governo imperial passou a se organizar frente a essa legislação tendo como objetivo garantir os cuidados das crianças negras que nasceriam livres. Porém, são poucos os estudos que apontam a existência de iniciativas tanto dessas instituições como do próprio governo que visassem à educação das crianças negras. Muitas dessas instituições destinadas à acolhida dos nascidos livres nunca receberam uma criança sequer.

Com o decorrer desse processo, torna-se visível a interferência na articulação da legislação como previsto nos debates abolicionistas. Conforme Fonseca (2001), a articulação entre abolição e educação

tal como se deu nos debates relativos à libertação do ventre não foi colocada em destaque para proteger as crianças que nasceriam livres. No fundo, o que ela verdadeiramente expressa é a tentativa de minimizar o impacto que o fim do trabalho escravo poderia gerar na sociedade brasileira que receberia um número significativo de indivíduos originários do cativeiro na condição de cidadãos livre (FONSECA, 2001, p. 13).

Ressalva-se que, nesse cenário, a educação voltada para a população negra presente nos debates e discussões sobre a abolição estaria ligada ao receio de uma emancipação demasiado abrupta e, consequentemente, a preocupações acerca da mão de obra (BARROS, 2005a).

Quanto a esse contexto, Silva e Araújo (2005) afirmam que, após a abolição da escravatura, várias tentativas foram realizadas a fim de regulamentar o ensino público brasileiro por meio de diferentes reformas educacionais. Porém, ao se analisar as implicações dessas medidas na progressividade educacional dos negros paulistas tanto do século XIX como do século XX, concluiu-se que:

Revista da ABPN • v. 12, n. Ed. Especial - Caderno Temático: "Africanos, escravizados, libertos biografias, imagens e experiências atlânticas” • agosto de 2020, p. $734-754$ 
[...] a população negra teve presença sistematicamente negada na escola: a universalização ao acesso e à gratuidade escolar legitimaram uma "aparente" democratização, porém, na realidade, negaram condições objetivas e materiais que facultassem aos negros recém-egressos do cativeiro e seus descendentes um projeto educacional, seja este universal ou específico (SILVA; ARAÚJO, 2005, p.71).

Barros (2005b) constata, em dissertação intitulada "Negrinhos que por ahi andão: a escolarização da população negra em São Paulo (1870 - 1920)", a existência de discursos acerca da importância da educação para o segmento negro e a comprovação da presença de alunos dessa origem em escolas públicas. No entanto, por outro lado, é evidente, nas fontes bibliográficas, as dificuldades direcionadas tanto no ingresso quanto em relação à permanência desse público.

Constata-se que as primeiras oportunidades concretas de educação escolar e ascensão da população negra surgem ainda no Estado Republicano, quando o desenvolvimento industrial dos anos finais do século XIX impulsionou o ensino popular e profissionalizante. O chamado ensino popular é constituído mediante a organização de grupos escolares urbanos, que ofereciam Ensino Primário de melhor qualidade, e de escolas isoladas, com cursos diurnos e noturnos instalados em bairros operários e fazendas (SILVA; ARAÚJO, 2005).

Garcia (2007) esclarece, ainda, que as oportunidades educacionais para essas populações só serão mais visíveis no início do século XX, especificamente nas décadas de 1920 e 1930, com a disseminação de escolas técnicas para atender à demanda do mercado de trabalho. Para Silva e Araújo (2005), tais escolas tiveram o papel de propiciar a escolarização profissional e superior de uma pequena parcela da população negra, em contraponto a uma conspiração de circunstâncias sociais que mantinham os negros fora da escola.

\section{EDUCAÇÃO PARA QUEM? UMA PAUTA COTIDIANA PARA O MOVIMENTO SOCIAL NEGRO}

Os tensionamentos acerca das pautas na educação para a população negra partem de modo incisivo por meio do Movimento Social Negro. As diferentes mobilizações

Revista da ABPN • v. 12, n. Ed. Especial - Caderno Temático: "Africanos, escravizados, libertos biografias, imagens e experiências atlânticas” • agosto de 2020, p. $734-754$ 
adentram setores políticos de diversas ordens na busca pela equidade de direitos desta parcela da população no campo educacional. As lutas neste âmbito são históricas no Brasil e demonstram a relevância deste movimento no contexto nacional inclusive na área acadêmica.

A parcela da população negra que obteve sucesso com o acesso à educação passa a formar uma nova classe social independente e intelectualizada. A mobilização social desta configura-se como um mecanismo de autoproteção e resistência, servindo de base para as primeiras reivindicações sociais negras após a abolição e para o fortalecimento do Movimento Social Negro (SILVA; ARAÚJO, 2005).

Conforme Gomes (2011a), após a abolição e desde meados do século XX, a educação era vista como pauta prioritária das reivindicações organizadas pelo Movimento Social Negro. A autora enfatiza que quanto mais a população negra liberta passava a figurar na história um status político de cidadão (mesmo sendo abstrata tal configuração no contexto da desigualdade racial pós-abolição), mais a organização frente às lutas acerca dos direitos por educação se fortalecia. Pautas como a inclusão de História e Cultura do Negro já são levantadas nesse período.

As lutas que obtiveram forte repercussão na década de 1920 tinham como objetivo a igualdade de direitos e uma Educação ampla, que propiciasse aos negros recém-egressos da escravidão e a seus descendentes a participação nos eventos culturais, sociais, políticos e econômicos em curso. Os discursos eram em prol da valorização, do respeito, do prestígio, da honorabilidade e da ascensão social através da educação do negro (SILVA; ARAÚJO, 2005).

De acordo com Barros (2005b), a São Paulo da década de 1920 caracterizava-se pelo fortalecimento do Movimento Social Negro frente às pautas educacionais. Nessa época, utilizava-se como principal estratégia a produção de jornais. A denominada Imprensa Negra visava denunciar e reverter o quadro de marginalização de libertos, exescravizados e seus descendentes. Suas produções enfocavam as mais diversas mazelas que afetavam a população negra no campo do trabalho, da habitação, da educação e da saúde (DOMINGUES, 2007).

A Frente Negra Brasileira (FNB), associação de caráter político, recreativo e beneficente, nasce em São Paulo no período após abolição, visando a se tornar uma

Revista da ABPN • v. 12, n. Ed. Especial - Caderno Temático: "Africanos, escravizados, libertos biografias, imagens e experiências atlânticas" • agosto de 2020, p. $734-754$ 
articulação nacional. Com diferentes departamentos, incluía também a tomada de ações educacionais específicas, como é o caso das escolas com cursos de alfabetização de crianças, jovens e adultos. (GOMES, 2011a; SILVA; ARAÚJO, 2005).

Quanto ao crescimento da FNB, Domingues (2007) afirma que a associação se expandiu por estados brasileiros, entre eles "Rio de Janeiro, Minas Gerais, Rio Grande do Sul, Bahia e Pernambuco" (DOMINGUES, 2007, p. 106). Tendo alcançado um relevante nível organizacional, além de manter o foco na escola, foram desenvolvidos

grupo musical e teatral, time de futebol, departamento jurídico, além de oferecer serviço médico e odontológico, cursos de formação política, de artes e ofícios, assim como publicar um jornal, o A Voz da Raça (DOMINGUES, 2007, p.106).

Gomes (2011a) ressalva a experiência do Teatro Experimental do Negro (TEN) na cidade do Rio de Janeiro, projeto que alvitrava trabalhar pela valorização social do negro no Brasil por meio da educação, da cultura e da arte. Segundo a autora:

[...] o TEN alfabetizava seus primeiros participantes, recrutados entre operários, empregados domésticos, favelados sem profissão definida, modestos funcionários públicos - e oferecia-lhes uma nova atitude, um critério próprio que os habilitava também a ver, enxergar o espaço que ocupava o grupo afrobrasileiro no contexto nacional (GOMES, 2011a, p.140).

Abadias do Nascimento (2004), em seu artigo intitulado "Teatro Experimental do Negro: trajetórias e reflexões", descreve que, por meio da resposta da imprensa e de outros setores da sociedade, esse movimento e sua própria denominação surgem como um fermento revolucionário. Era previsível o destino polêmico do TEN em uma sociedade em que a menção pública da palavra negro provocava sussurros de indignação e em que há séculos se tentava esconder o racismo e a discriminação racial com o mito da democracia racial.

Enfrentando o tabu das relações raciais até mesmo com os movimentos culturais aparentemente mais abertos e progressistas, pois até esses não tinham "papel” para atores negros mesmo em peças nativas. Nascimento (2004) afirma que as estratégias criadas estavam organizadas em duas frentes:

Revista da ABPN • v. 12, n. Ed. Especial - Caderno Temático: "Africanos, escravizados, libertos biografias, imagens e experiências atlânticas" • agosto de 2020, p. $734-754$ 
[...] promover, de um lado, a denúncia dos equívocos e da alienação dos chamados estudos afro-brasileiros, e fazer com que o próprio negro tomasse consciência da situação objetiva em que se achava inserido (NASCIMENTO, 2004, p. 210, 211).

Dentre as lutas do, aqui denominado, Movimento Social Negro brasileiro após 1970, as reivindicações no campo da educação são constantes. Cardoso (2006) aponta a comprovação por parte dos movimentos de reconhecimento da educação como campo privilegiado de enfrentamento do racismo. Esta afirmativa deve-se à compreensão do sistema público de ensino no Brasil que atribui à responsabilização acerca do baixo desempenho da criança e do jovem negro aos próprios negros na explicação hegemônica para esse crítico desempenho.

De acordo com Gomes (2011b), na década de 1980, durante o processo de abertura política e redemocratização, o Movimento Social Negro passa a atuar em conjunto com outros movimentos sociais, principalmente aqueles de caráter identitário. Suas pautas problematizam o enfoque de classe social presente nas reivindicações dos movimentos da época, indagando

o Estado, a esquerda brasileira e os movimentos sociais sobre o seu posicionamento neutro e omisso diante da centralidade da raça na formação do país. O Movimento Negro reivindica que a questão racial deveria ser compreendida como uma forma de opressão e exploração estruturante das relações sociais e econômicas brasileiras, acirrada pelo capitalismo e pela desigualdade social (GOMES, 2011b, p.3).

Esse período também possibilitou o surgimento de um novo perfil de intelectual, que passa a pesquisar as relações raciais, sobretudo no campo educacional. Oriundo da consolidação da pós-graduação em Educação, tem-se o gradual ingresso de intelectuais negros nas universidades públicas e a aparição de novos grupos de pesquisa educacional e de congressos voltados para a temática "negro e educação". Cabe ressaltar que nessa época são discutidos temas como a discriminação do negro nos livros didáticos e a necessidade de inserção da temática racial e da História da África nos currículos (GOMES, 2011b).

Cardoso (2006) ressalta que os discursos enfáticos do Movimento Social Negro no fim das décadas de 1980 e 1990, denunciando os estereótipos, o racismo e as

Revista da ABPN • v. 12, n. Ed. Especial - Caderno Temático: "Africanos, escravizados, libertos biografias, imagens e experiências atlânticas” • agosto de 2020, p. $734-754$ 
discriminações raciais, pressionam a academia a incorporar a dimensão étnico-racial no levantamento de novos indicadores sociais no Brasil. Ganhando paulatinamente mais espaço em pesquisas acerca da política educacional, passa a ser problematizado diferentes questionamentos, tendo, assim, estas questões participação de forma marcante na Constituinte (1988) e na elaboração da nova Lei de Diretrizes e Bases da Educação (Lei $\mathrm{n}^{\circ}$ 9.394/96).

Gomes (2011b) traz para o debate o fato de o Movimento Social Negro reivindicar a inserção da questão racial na escola, educação básica e universidade para todos. Entretanto, o movimento identifica que as políticas públicas de educação pós-ditadura militar, de caráter universal, ao ser implementadas não atendiam à grande massa da população negra e não se comprometiam com a superação do racismo. É nesse contexto que as Políticas de Ações Afirmativas começam a se configurar como uma possibilidade às demandas do Movimento Social Negro e deste modo passam a afirmar o lugar da educação básica e superior como um direito social e, desse modo, como direito à diversidade étnico-racial.

Por conseguinte, a educação permanece sendo um dos principais campos de luta do Movimento Social Negro no Brasil. As articulações entre a educação escolar e os processos educativos que se dão no âmbito dos movimentos sociais, nos processos políticos e nos grupos culturais são bandeiras das lutas na busca da garantia a processos, políticas e práticas educativas acerca da vivência da igualdade social, da equidade e da justiça social aos diferentes grupos sociais e étnico-raciais (GOMES, 2011a).

Nesse sentido, Gomes (2011a) afirma que o Movimento Social Negro luta historicamente por um projeto educativo que se choca, muitas vezes, com a racionalidade hegemônica que impera na teoria social e pedagógica cercada pelo mito da democracia racial. A autora reforça que o projeto de luta do Movimento pela e na Educação:

[...] apresenta outro tipo de saber, construído numa história em que a diversidade étnico-racial sempre esteve presente, em que a alteridade sempre esteve pautada, não só no reconhecimento do Outro, mas na luta política de ser reconhecido como um outro que tem direito de viver a sua diferença e ver sua cultura e sua identidade respeitadas tanto no cotidiano das escolas e dos seus currículos quanto na política educacional (GOMES, 2011a, p.137).

Revista da ABPN • v. 12, n. Ed. Especial - Caderno Temático: "Africanos, escravizados, libertos biografias, imagens e experiências atlânticas” • agosto de 2020, p. $734-754$ 
A Lei Federal no 10.639/2003 incide sobre todo o âmbito educacional, pois propõe uma nova postura para a educação, uma proposta de política curricular que alvitra aos brasileiros uma cidadania forjada em um novo projeto de sociedade. Essa Política de Ação Afirmativa não requer novos conteúdos, mas sim estabelecer o reconhecimento das diferenças nas relações que permeiam o campo educacional, ou seja, educação para as relações étnico-raciais.

Gomes (2011b) dá destaque à referida legislação a partir da complexidade do campo das relações raciais brasileiras sobre a qual reflete. Isso quer dizer ser necessário ir além da adoção de programas e projetos específicos voltados para a diversidade étnicoracial, realizados de forma aleatória e descontinuada, mas trabalhada como uma política curricular na qual

\begin{abstract}
a inserção da questão racial nas metas educacionais do país, no Plano Nacional da Educação, nos planos estaduais e municipais, na gestão da escola, nas práticas pedagógicas e curriculares e na formação inicial e continuada de professores(as) de forma mais contundente (GOMES, 2011b, p.117).
\end{abstract}

Deste modo, a proposição legislativa é educar para relações étnico-raciais positivas e promover um processo de inclusão na educação brasileira. "É fazer emergir as dores e os medos que têm sido gerados na busca de entender que o sucesso de uns tem o preço da marginalização e da desigualdade impostas a outros” (BRASIL, 2007, p.34).

A necessidade de reconhecimento, valorização e afirmação de direitos da população negra, no que diz respeito à educação, passou a ser particularmente apoiada com a promulgação da Lei Federal n ${ }^{\circ} 10.639 / 2003$. Esses pressupostos estão interligados na medida em que reconhecer exige a valorização e o respeito às pessoas negras. Significa, assim, que a educação deve buscar compreender seus valores e lutas, bem como ser sensível ao sofrimento causado por tantas formas de desqualificação:

[...] apelidos depreciativos, brincadeiras, piadas de mau gosto sugerindo incapacidade, ridicularizando seus traços físicos, a textura de seus cabelos, fazendo pouco das religiões de raiz africana. Implica criar condições para que os estudantes negros não sejam rejeitados em virtude da cor da sua pele, menosprezados em virtude de antepassados seus terem sido explorados como

Revista da ABPN • v. 12, n. Ed. Especial - Caderno Temático: "Africanos, escravizados, libertos biografias, imagens e experiências atlânticas” • agosto de 2020, p. 734-754 
escravos, não sejam desencorajados de prosseguir estudos, de estudar questões que dizem respeito à comunidade negra. (BRASIL, 2007, p.33).

Para Gomes (2005), a ênfase na identidade resulta, também, na ênfase da diferença. Tendo em vista que a busca da identidade por parte de um grupo social evoca a diferença deste em relação à sociedade ou a outro grupo e instituição, ela possui um processo de elaboração e diminuição das diferenças internas do próprio grupo e dos vários grupos que formam.

Nessa perspectiva, a presente legislação, enquanto política curricular, permite aos negros o direito de se reconhecerem na cultura nacional e expressarem suas visões de mundo próprias de sua identidade suprimidas pelo racismo, o qual imprime marcas negativas na subjetividade dos negros e também na dos que os discriminam (BRASIL, 2007).

Outra relevante discussão, trazida por Silveira et.al (2013), diz respeito aos limites reconhecidos após dez anos de existência da Lei Federal no 10.639/2003 no currículo da educação brasileira e no cotidiano escolar. Os principais desafios identificados são nos componentes da ordem metodológica e pedagógica, sendo necessário aprofundar a compreensão dos sentidos e fazeres de uma educação para as relações étnico-raciais, na qual as práticas pedagógicas contribuam para o entendimento da convivência em uma sociedade multicultural, por meio de metodologias que enfrente de forma incisiva o racismo e a discriminação racial.

No contexto de um processo de educação universal, cidadã e democrática, na qual as instituições educacionais voltem o olhar e produção de conhecimento para a realidade social do país, esta legislação se torna imprescindível nos diferentes campos dos saberes, rompendo com a lógica de "ensino em datas comemorativas" e racismo e discriminação racial estruturais que adentram cotidianamente o espaço escolar.

Contribuindo com a discussão, Oliveira (2020) descreve, dentre os diferentes enfrentamentos colocados atualmente, a conjuntura social e política do país, que acabam por representar uma ameaça real às Diretrizes Curriculares Nacionais para a Educação das Relações Étnico-Raciais e para o Ensino de História e Cultura Afro-Brasileira e Africana. Segundo o autor, a ameaça surge "como um monstro atrás da porta, prestes a nos engolir e sepultar definitivamente nossas energias de luta" (OLIVEIRA, 2020, p.12).

Revista da ABPN • v. 12, n. Ed. Especial - Caderno Temático: "Africanos, escravizados, libertos biografias, imagens e experiências atlânticas” • agosto de 2020, p. $734-754$ 
Em relação às contribuições emancipatórias da luta do Movimento Social Negro, que cotidianamente enfrenta e reconstrói as pautas e propostas no campo educacional, Gomes (2018) descreve o Movimento por meio de fazeres e saberes educadores, sabedorias ancestrais, com uma trajetória de luta pelo combate ao racismo, discriminação racial e emancipação social no Brasil, ao longo da história social, política e educacional, onde seus representantes constroem aprendizados de ordem intelectual, política e humana.

\section{CONSIDERAÇÕES FINAIS}

A partir deste estudo, torna-se visível, no contexto das relações sociais brasileira, que a população negra é atravessada por experiências históricas de racismo e discriminação racial, construídas por meio de vertentes hierarquizadas das estratégias de branqueamento e mito da democracia racial.

Neste cenário, o campo da educação, historicamente constituído por interdições de acesso e permanência do povo negro, é também espaço da reprodução social de práticas racistas. Seu papel na construção de cidadania necessita cotidianamente pautar o enfrentamento do racismo, contando com políticas públicas e legislação pertinente, assim como, a participação da sociedade.

O Movimento Social Negro demonstra protagonismo na construção de políticas públicas educacionais. Possui destaque os caminhos trilhados com a Lei Federal $\mathrm{n}^{\circ}$ 10.639/2003, que em consonância com as Diretrizes Curriculares Nacionais para a Educação das Relações Étnico-Raciais, materializa o espaço de luta pelo combate do racismo e discriminação racial nos espaços educacionais formais e não formais, em uma perspectiva comprometida com um contexto social equânime e emancipatório.

\section{REFERÊNCIAS BIBLIOGRÁFICAS}

ALBUQUERQUE, Walmira Ribeiro; FRAGA FILHO, Walter. Uma história do negro no Brasil. Universidade Federal da Bahia. Salvador: Centro de Estudos AfroOrientais. IV. Brasília: Fundação Cultural Palmares, 321 p. 2006. Disponível em: <http://www.ceao.ufba.br/livrosevideos/pdf>. Acesso em: 07/06/2020.

Revista da ABPN • v. 12, n. Ed. Especial - Caderno Temático: "Africanos, escravizados, libertos biografias, imagens e experiências atlânticas” • agosto de 2020, p. $734-754$ 
BARROS, Surya Aaronovich Pombo. Discutindo a escolarização da população negra em São Paulo entre o final do século XIX e início do século XX. In: ROMÃO, Jerus (Org). História da Educação do Negro e outras histórias. Brasília: Ministério da Educação, Secretaria de Educação Continuada, Alfabetização e Diversidade, 2005a.

. Negrinhos que por ahi andão: a escolarização da população negra em São Paulo (18701920). Dissertação (Mestrado em História da Educação e Historiografia). Universidade de São Paulo. Faculdade de Educação. SP, 2005b.

BOSI, Alfredo. A escravidão entre dois liberalismos. Revista Estudos Avançados, São Paulo, v.2, n.3, 1989.

BRASIL. Lei $n^{\circ} 10.639$, de 9 de janeiro de 2003. Altera a Lei $\mathrm{n}^{\mathrm{a}}$ no 9.394, de 20 de dezembro de 1996, que estabelece as diretrizes e bases da educação nacional, para incluir no currículo oficial da Rede de Ensino a obrigatoriedade da temática "História e Cultura Afro-Brasileira", e dá outras providências. Disponível em < www.planalto.gov.br/ccivil_03/leis/2003/L10.639.htm> Acesso em 12/06/2020.

. Ministério da Educação. Programa Ética e Cidadania: construindo valores na escola e na sociedade: relações étnico-raciais e de gênero. Organização FAFE - Fundação de Apoio à Faculdade de Educação (USP), equipe de elaboração Ulisses F. Araújo... [et al.]. Brasília: MEC, 2007.

.Ministério da Educação. Diretrizes Curriculares Nacionais para a Educação das Relações Étnico-Raciais e para o Ensino de História e Cultura Afro-Brasileira e Africana. Brasília: MEC, 2004

.Ministério da Educação. Instituto Nacional de Estudos e Pesquisa Educacionais Anísio Teixeira. Censo Escolar Educacenso - O Item Cor/Raça no Censo Escolar da Educação Básica. Brasília: MEC/INEP,2015.

Conselho Nacional de Educação. Câmara de Educação Básica. Parecer CNE/CEB $N^{o}$. 13/2009. Parecer homologado Despacho do Ministro, publicado no D.O.U. de 24/9/2009, Seção 1, p. 13. Brasília: MEC,2009.

. Decreto $n^{\circ}$. 7.611, de 17 de novembro de 2011. Dispõe sobre a educação especial, o atendimento educacional especializado e dá outras providências. Disponível em: <http://www.planalto.gov.br/ccivil_03/_Ato2011-2014/2011/Decreto/D 7611.htm \#art8>. Acesso em: 08/06/2020.

. Decreto $n^{\circ} 1.331-A$, de 17 de fevereiro de 1854. Aprova o Regulamento para a reforma do ensino primário e secundário do Município da Corte. Disponível em: <http://www2.camara.leg.br/legin/fed/decret/1824-1899/decreto 1331-a-17-fevereiro-1854590146-publicacaooriginal-115292-pe.html>. Acesso em: 12/06/2020.

Lei 2.040 de 28 de setembro de 1871. Declara de condição livre os filhos de mulher escrava que nascerem desde a data desta lei, libertos os escravos da Nação e outros, e providencia sobre a criação e tratamento aqueles filhos menores e sobre a libertação anual de escravos. Disponível em: < http://www.planalto.gov.br/ccivil_03/leis/lim/LIM2040.htm>. Acesso em: 12/06/2020.

CALDAS, Alcides dos Santos; SANTOS, Antonio Luiz Moreira; SANTOS, Ramon. Conferência de Durban: Implementação e desenvolvimento das políticas de promoção da igualdade no Brasil. In: XI CONGRESSO LUSO AFRO BRASILEIRO DE CIÊNCIAS SOCIAIS. Anais[...] Disponível em: <www.xiconlab.eve tos.dype.com.b r/resources/ anais>. Acesso em:07/06/2020.

CARDOSO, Nadia Maria. Instituto Steve Biko: juventude negra mobilizando-se por políticas de afirmação dos negros no ensino superior. 2006. Dissertação (Mestrado em Educação e

Revista da ABPN • v. 12, n. Ed. Especial - Caderno Temático: "Africanos, escravizados, libertos biografias, imagens e experiências atlânticas" • agosto de 2020, p. 734-754 
Contemporaneidade). Universidade do Estado da Bahia. Programa de Pós-Graduação em Educação e Contemporaneidade da Universidade do Estado da Bahia. Salvador, 2006.

DOMINGUES, Petrônio. Movimento Negro Brasileiro: alguns apontamentos históricos. Revista Tempo, Niterói, v.12, n.23, 2007.

GARCIA, Renísia Cristina. Identidade fragmentada: um estudo sobre a história do negro na educação brasileira: 1993-2005. Brasília: Instituto Nacional de Estudos e Pesquisas Educacionais Anísio Teixeira, 2007.

GONÇALVES, Luiz Alberto Oliveira. Negro e educação no Brasil. In: LOPEZ, Eliane Marta Teixeira (Org.). 500 anos da Educação no Brasil. Belo Horizonte: Autêntica, 2010.

GOMES, Nilma Lino. O movimento negro no Brasil: ausências, emergências e a produção dos saberes. Revista Política \& Sociedade, Florianópolis, v.10, n. 18, 2011 a.

Diversidade étnico-racial, inclusão e equidade na educação brasileira: desafios, políticas e práticas. Revista Brasileira de Política e Administração da Educação, São Paulo, v.27, n.1, p. $2011 b$.

Alguns termos e conceitos presentes no debate sobre relações raciais no Brasil: uma breve discussão. In: Educação anti-racista: caminhos abertos pela Lei Federal $n^{o}$ 10.639/03. Secretaria de Educação Continuada, Alfabetização e Diversidade. Brasília: Secretaria de Educação Continuada, Alfabetização e Diversidade, 2005.

.O Movimento Negro Educador: saberes construídos nas lutas por emancipação. Petrópolis , RJ: Vozes, 154p, 2018.

NASCIMENTO, Abadias. Teatro Experimental do Negro: trajetória e reflexões. Revista Estudos Avançados, São Paulo. V.18, n.50, 2004.

MAGGIE, Ivonne; FRY, Peter. A reserva de vagas para negros nas universidades brasileiras. Revista Estudos Avançados, São Paulo, v18, n.50, 2004.

MESSIAS, Marta Iris Camargo da Silveira. O movimento social negro: da contestação as políticas de ações afirmativas e a implicação para aplicação da Lei Federal 10.639/03 - o caso da rede municipal de ensino de Santa Maria - RS. 2009. Tese (Doutorado em Educação). Universidade Federal da Bahia. Faculdade de Educação. Salvador, 2009.

OLIVEIRA, Luiz Fernandes. Opção decolonial e antirracismo na educação em tempos neofacistas. Revista da Associação Brasileira de Pesquisadores Negros, Uberlândia, v.12, n.32, 2020.

OLIVEN, Arabela Campos. Ações afirmativas, relações raciais e política de cotas nas universidades: Uma comparação entre os Estados Unidos e o Brasil. Revista Educação, Porto Alegre, v.61, n.1, 2007.

ROCHA, Edmar José. Auto-declaração de cor e/ou raça entre alunos (as) paulistanos (as) do ensino fundamental e médio: um estudo exploratório. 2005. Dissertação (Mestrado em Psicologia Social). Pontifícia Universidade Católica de São Paulo. São Paulo.2005.

SILVA, Mozart Linhares. Miscigenação e Biopolítica no Brasil. Revista Brasileira de História \& Ciências Sociais, São Leopoldo, v. 4, n. 8, 2012.

Revista da ABPN • v. 12, n. Ed. Especial - Caderno Temático: "Africanos, escravizados, libertos biografias, imagens e experiências atlânticas" • agosto de 2020, p. $734-754$ 
SILVA, Geraldo; ARAÚJO, Márcia. Da interdição escolar às ações educacionais de sucesso: escolas dos movimentos negros e escolas profissionais, técnicas e tecnológicas. In: ROMÃO, Jeruse (Org). História da Educação do Negro e outras histórias. Brasília: Ministério da Educação, Secretaria de Educação Continuada, Alfabetização e Diversidade, 2005.

SILVEIRA, PAULO ROBERTO C; SILVEIRA, MARTA IRÍS CAMARGO MESSIAS;TIER, CENIR GONÇALVES. As relações étnico raciais e a implantação da Lei 10.639: reflexões necessárias e alguns apontamentos metodológicos. In: Núcleo Interdisciplinar de Educação: Articulação de contextos \& saberes nos (per)cursos de licenciatura da Unipampa / organizadoras Marta Iris Camargo Messias da Silveira e Paula Bianchi- Florianópolis: Tribo da Ilha, 240p, 2013.

SILVERIO, Walter. Roberto. Ação Afirmativa: uma política pública que faz a diferença. In: Pacheco, Jairo Queiroz; SILVA, Maria Nilza. O negro na universidade: o direito à inclusão. Brasília: Fundação Cultural Palmares, 151p, 2007.

SCHWARCZ. Lilia Moritz. Racismo "à brasileira". In: ALMEIDA, Heloisa Buarque de; SZWAKO, José Eduardo (orgs). Diferenças, igualdade. São Paulo: Berlendis \& Vertecchia, 2009.

TELLES, Edward. Race in Another America: The Significance of Skin Color in Brazil. Princeton: Princeton University Press, 2004.

Recebido 03/07/2020

Aprovado em 22/07/2020

Revista da ABPN • v. 12, n. Ed. Especial - Caderno Temático: "Africanos, escravizados, libertos biografias, imagens e experiências atlânticas” • agosto de 2020, p. $734-754$ 